\title{
In Vivo Evidence in the Brain for Lithium Inhibition of Glycogen Synthase Kinase-3
}

\author{
Todd D Gould', Guang Chen' and Husseini K Manji**, \\ 'Laboratory of Molecular Pathophysiology, Mood and Anxiety Disorders Program, National Institute of Mental Health, Bethesda, MD, USA
}

\begin{abstract}
There is considerable interest in the possibility that small-molecule glycogen synthase kinase-3 inhibitors may have utility in the treatment of bipolar disorder, since glycogen synthase kinase-3 is a target of lithium. Although the in vitro inhibition of glycogen synthase kinase-3 by lithium occurs with a $K_{i}$ of $\mathrm{I}-2 \mathrm{mM}$, the degree of inhibition of this enzyme in the mammalian brain at therapeutically relevant concentrations has not fully been established. The transcription factor $\beta$-catenin is an established marker of glycogen synthase kinase-3 inactivation because cytoplasmic levels are increased by inhibition of the enzyme. In this study, we measured $\beta$-catenin protein levels after treatment with therapeutically relevant doses of lithium, valproate, and carbamazepine. Western blot revealed that 9 days of treatment with lithium and valproate, but not carbamazepine, increased $\beta$-catenin protein levels in soluble fractions from the frontal cortex. The level of $\beta$-catenin in the particulate fraction, which is not directly regulated by glycogen synthase kinase-3, did not change with any of the three drugs. Furthermore, real-time PCR revealed that lithium significantly decreased $\beta$-catenin mRNA levels, which may represent compensation for an increase in $\beta$-catenin stability. These results strongly suggest that lithium significantly inhibits brain glycogen synthase kinase-3 in vivo at concentrations relevant for the treatment of bipolar disorder.

Neuropsychopharmacology (2004) 29, 32-38, advance online publication, 27 August 2003; doi: I 0. I038/sj.npp. I 300283
\end{abstract}

Keywords: valproic acid; GSK-3; Wnt pathway; mania; depression; manic-depressive illness

\section{INTRODUCTION}

Lithium is the most well-established treatment for the manic phase of bipolar disorder. However, in spite of the clinical utility of this drug, the precise mechanism by which it exerts its therapeutic effects remains unknown (Gould et al, 2002). Lithium is documented to have some degree of inhibition of a number of enzymes (Davies et al, 2000), through competition for magnesium (Amari et al, 1999b; Gurvich and Klein, 2002; Ryves and Harwood, 2001; York et al, 1995). However, only a few are significantly inhibited at therapeutic concentrations $(0.5-1.2 \mathrm{mM}$ ) (Gould et al, 2002; Phiel and Klein, 2001; Shaldubina et al, 2001). In mammalian systems, lithium - at therapeutically relevant concentrations - inhibits a group of at least four related phosphomonoesterases (inositol polyphosphate 1-phosphatase (IPPase), inositol monophosphate phosphatase (IMPase), fructose 1,6-bisphosphatase 1-phosphatase (FBPase), and bisphosphate nucleotidase (BPNase)) (York et al, 1995),

\footnotetext{
*Correspondence: Dr HK Manji, Laboratory of Molecular Pathophysiology, Building 49, Room BIEEI6, 49 Convent Drive, Bethesda MD 20892-4405, USA, Tel: + I 301 496 9802, Fax: + I 3014800123 , E-mail: manji@nih.gov

This article is a 'United States Government Work' paper as defined by the US Copyright Act.

Received 09 February 2003; revised 26 May 2003; accepted 30 June 2003

Online publication: 2 July 2003 at http://www.acnp.org/citations/ Npp07020303059/default.pdf
}

the metabolic enzyme phosphoglucomutase (PGM) (Masuda et al, 2001; Ray et al, 1978; Rhyu et al, 1984), and glycogen synthase kinase-3 (GSK-3) (Klein and Melton, 1996; Stambolic et al, 1996). Furthermore, in view of the critical role of protein phosphorylation in the central nervous system (CNS), investigators have studied lithium's effects on a variety of protein kinases; interestingly, lithium has a major direct effect on GSK-3 activity, but no other kinases investigated (Davies et al, 2000; Klein and Melton, 1996; Stambolic et al, 1996).

A number of signaling pathways regulate GSK-3 function. For example, protein kinases including Akt, p70 S6 kinase, Rsk, protein kinase $\mathrm{C}(\mathrm{PKC})$, and cAMP-dependent protein kinase (PKA) deactivate GSK-3 by phosphorylation of an inhibitory serine site (Cohen and Frame, 2001; Doble and Woodgett, 2003; Grimes and Jope, 2001). GSK-3 has a large number of targets within the cell (Cohen and Frame, 2001; Grimes and Jope, 2001). The effects of GSK-3 on transcription factors such as c-Jun, heat shock factor-1 (HSF-1), and nuclear factor of activated T cells (NFAT) are particularly noteworthy, and have drawn considerable interest (Frame and Cohen, 2001; Grimes and Jope, 2001). Generally, GSK-3 activity results in suppression of the activity of transcription. Conversely, inhibition of GSK-3 appears to activate these transcription factors (Grimes and Jope, 2001). Thus, GSK-3 is well positioned to integrate signals from multiple, diverse, signaling pathways, a function that is undoubtedly critical in the CNS. It is this position that has attracted the attention of the clinical neuroscience community. It is 
hypothesized that GSK-3's modulatory position in the cell allows it to be a critical regulator of many of the plastic processes that are thought to underlie the therapeutic effects of lithium (Gould and Manji, 2002; Gurvich and Klein, 2002).

GSK-3 is also a critical regulator of the Wnt signaling pathway. Wnt secreted glycoproteins bind to the frizzled family of extracellular receptors, resulting in a signal that is transduced via an intracellular protein, disheveled. Signaling through disheveled results in inhibition of GSK-3 (Wodarz and Nusse, 1998). GSK-3's target in the Wnt pathway is $\beta$-catenin, which is found in two functional reservoirs within the cell - a cytoplasmic and a membraneassociated pool. The cytoplasmic pool functions as a transcription factor that translocates to the nucleus, and is involved in transmitting the Wnt signal in combination with transcription factors belonging to T-cell factor (tcf)/ lymphoid enhancing factor (lef) family. The membraneassociated pool interacts with cadherin on the cell surface. Phosphorylation of cytoplasmic $\beta$-catenin by GSK-3 leads to ubiquitin-dependent degradation (Peifer and Polakis, 2000; Sharpe et al, 2001). Thus, inhibition of GSK-3 prevents phosphorylation, and subsequent degradation of $\beta$-catenin. Cytosolic $\beta$-catenin is therefore often used as an in vivo marker of GSK-3 activity.

Lithium has clearly been demonstrated to inhibit GSK-3 in vitro at concentrations approximating those attained in plasma clinically (Klein and Melton, 1996; Stambolic et al, 1996). The $K_{\mathrm{i}}$ for lithium's inhibition of GSK-3 was initially reported by two laboratories as $2 \mathrm{mM}$ (Klein and Melton, 1996), or between 1 and $2 \mathrm{mM}$ (Stambolic et al, 1996). Lithium appears to inhibit GSK-3 through competition for magnesium (Gurvich and Klein, 2002; Ryves and Harwood, 2001) and the afore-mentioned studies estimated lithium's ability to inhibit GSK-3 in the presence of $10 \mathrm{mM}$ magnesium. While brain intracellular magnesium concentrations are not precisely known, they are estimated to be between 0.2 and $1.2 \mathrm{mM}$ (Amari et al, 1999a; Brocard et al, 1993; Gee et al, 2001; Gotoh et al, 1999; Li-Smerin et al, 2001), suggesting that the concentration of lithium required to significantly inhibit GSK-3's enzymatic activity in the brain is considerably lower than $1-2 \mathrm{mM}$. Furthermore, studies suggest that acute doses of lithium inhibit GSK-3mediated phosphorylation of tau in the 7-day-old rat brain (Elyaman et al, 2002; Munoz-Montano et al, 1997) and in the brain of starved mice (Planel et al, 2001). However, studies showing that a similar inhibition of lithium occurs in the adult mammalian brain in vivo at therapeutically relevant concentrations and time frame are lacking. These studies are clearly necessary to establish prior to ascribing therapeutic relevance in the treatment of bipolar disorder, and undertaking trials of selective GSK-3 inhibitors in the disease. Lithium has also been shown to increase phosphorylation of GSK-3 $\beta$ (Bhat et al, 2000; De Sarno et al, 2002; Lee et al, 2003) and $\alpha$ (Chalecka-Franaszek and Chuang, 1999) at their respective inhibitory serine sites. Since GSK-3 activity toward $\beta$-catenin in the Wnt pathway is not modulated by phosphorylation (Ding et al, 2000; Yuan et al, 1999a), $\beta$-catenin is an excellent target to attempt to separate this effect of lithium from a direct inhibitory effect. In order to determine if lithium inhibits GSK-3 in vivo, at concentrations relevant for the treatment of bipolar disorder, we treated rats with lithium, in addition to the structurally distinct mood stabilizers valproate and carbamazepine, utilizing cytosolic $\beta$-catenin as a marker of in vivo GSK-3 activity.

\section{MATERIALS AND METHODS}

\section{Animals}

All animal treatments, procedures, and care were approved by the NIMH Animal Care and Use Committee and followed the Guide for the Care and Use of Laboratory Animals (ISBN 0-309-05377-3). Male Wistar Kyoto rats 7-8 weeks of age from Harlan (Indianapolis, IN) were housed 2-3 per cage in a $12 \mathrm{~h}$ light/dark cycle with free access to water and food. Rat chow was custom produced by Bio-Serve (Frenchtown, $\mathrm{NJ}$ ). Chows containing the drugs, and control chow were identical with the exception of the added drug, and were produced at both a 'low' and 'normal' concentration for each drug (lithium carbonate, 1.2 and $2.4 \mathrm{~g} / \mathrm{kg}$; sodium valproate, 10 and $20 \mathrm{~g} / \mathrm{kg}$; carbamazepine, 2.5 and $5 \mathrm{~g} / \mathrm{kg}$ ). The dose of lithium is that previously used by our group (Yuan et al, 1999b). Valproate doses were arrived at within our group by testing various doses. The carbamazepine dose has been used successfully by other groups (Lee et al, 2000; Weiss et al, 1987). Owing to the differences in metabolism between rats and humans, the ratios of carbamazepine and carbamazepine 10,11 epoxide (a primary carbamazepine metabolite) are reversed between the species (Marangos et al, 1985). However, both forms appear to be similarly active in the CNS (Weiss and Post, 1987). Rats were treated for 9 days because this time frame is generally that required for the initial therapeutic effects for the clinical treatment of mania in humans. Similar to the treatment approach used in humans, rats were first treated for 2 days with $1 / 2$ dose chow to minimize adverse effects; following this acclimatization period, the rats were treated for an additional 7 days with the full dose of the drug. In each group, 12 rats were treated with control, lithium, valproate, or carbamazepine chows and used for the protein analysis. A second set of 11 rats in each group treated with control, lithium, and valproate chow was used for the mRNA extraction experiments. All animals were provided with a second water bottle containing normal saline and daily bedding changes due to polyuria, a side effect of lithium treatment.

All rats were weighed and then killed by decapitation in the morning between 0900 and 1200. A side effect of treatment with these drugs is that rats undergoing treatment do not gain as much weight as nontreated animals. As expected, rat weights following treatment were significantly lower for all drug treatments compared to control treated animals. Weights of the animals utilized for the protein studies were: control $265 \pm 19.8 \mathrm{~g}$; lithium $227 \pm 23.0 \mathrm{~g}$; valproate $241 \pm 21.3 \mathrm{~g}$; carbamazepine $237 \pm 12.0 \mathrm{~g}$. Weights for the mRNA studies were: control $245 \pm 15.4 \mathrm{~g}$; lithium $202 \pm 12.5 \mathrm{~g}$; valproate $197 \pm 13.8 \mathrm{~g}$. Trunk blood was collected for analysis of drug levels. Drug serum levels were performed by Medtox laboratories (St Paul, MN) and were found to be within the therapeutic range. For the protein level experiments, serum blood levels were $0.80 \pm 0.18 \mathrm{mEq} / \mathrm{l}, \quad 56.8 \pm 39.2 \mu \mathrm{g} / \mathrm{ml}$, and $3.80 \pm 0.654 /$ 
$15.0 \pm 2.19 \mu \mathrm{g} / \mathrm{ml}$ for lithium, valproate, and carbamazepine (carbamazepine/carbamazepine 10,11 epoxide) treatment, respectively. For the mRNA extraction experiments, blood levels were $0.77 \pm 0.14 \mathrm{mEq} / \mathrm{l}$ and $77.7 \pm 25.3 \mu \mathrm{g} / \mathrm{ml}$, for lithium and valproate, respectively. It should be noted that valproate is rapidly metabolized in the rat, and there exists a wide degree of variation (the values vary day-to-day and hour-to-hour); this accounts for the wide variability in serum valproate levels, which has also been observed in other studies. Animals were killed - and the tissue subsequently processed - in groups (ie a group containing control, lithium, valproate, and carbamazepine chow treated rats). Frontal cortex, region anterior to white matter, and hippocampus were dissected immediately following decapitation. Brain specimens were then rapidly frozen in liquid nitrogen and stored at $-80^{\circ} \mathrm{C}$ until further analyses.

\section{Protein Extraction and Analysis}

The frontal cortex and hippocampus samples were homogenized in a hypotonic protein extraction buffer containing a protease inhibitor cocktail (SIGMA), and phosphatase inhibitor cocktails (I and II; SIGMA) by passing through a 21-gauge needle three times, followed by passing through a 25-gauge needle seven times. The homogenates were then centrifuged at $300 \mathrm{~g}$ for $12 \mathrm{~min}$ at $4{ }^{\circ} \mathrm{C}$ to remove nondissolved debris and nuclear portions. The particulate (representing largely membrane) and soluble (representing largely cytoplasmic) fractions were then separated by centrifugation at $17000 \mathrm{~g}$ for $20 \mathrm{~min}$ at $4{ }^{\circ} \mathrm{C}$. Protein concentrations were determined using the Bio-Rad protein assay kit (Bradford, 1976). The linearity of the protein concentration for immunoblotting was ascertained by resolution of selected concentrations of protein.

Subsequent protein immunoblotting was performed using previously described methods (Yuan et al, 2001). In brief, samples were subjected to SDS-PAGE on $8 \%$ gels. The amount of protein loaded was $0.375 \mu \mathrm{g}$ per lane. Proteins thus resolved were then electrophoretically transferred to nitrocellulose membranes. Nonspecific binding on the nitrocellulose was blocked with TBST, 5\% nonfat dry milk, and then incubated with monoclonal $\beta$-catenin antibodies (BD Transduction Laboratories catalog \# 610154, San Jose, CA), which recognize a distinct band at approximately $92 \mathrm{kDa}$. The antibodies for immunoblots were diluted 1:500, as per the manufacturer's recommendation. After blotting with secondary antibody (anti-mouse IgG; Cell Signaling Technology \# 7076, Beverly, MA), diluted 1:2000, the immunocomplex was detected with the ECL plus kit (Amersham Biosciences, Piscataway, NJ) and BioMax MR scientific imaging film (Kodak; New Haven, CT). Quantification of the immunoblots was performed by densitometric scanning of the film using a Kodak Image Station $440 \mathrm{CF}$ and Kodak 1D Image Analysis Software. Samples were normalized to the control animals within each group. Statistical analysis was performed by repeated measure analysis of variance followed by post hoc analysis (Student-Newman-Keuls). Significance was defined as $p<0.05$. Data are expressed as the mean \pm standard error.

\section{mRNA Extraction and Analysis}

Cortex samples were homogenized in Trizole reagent (Gibco BRL, Rockville, MD) using 10 passes through a 21-gauge needle followed by 10 passes through a 25-gauge needle. Samples were subsequently incubated at $-80^{\circ} \mathrm{C}$ for $1.5 \mathrm{~h}$ to increase yield, followed by chloroform extraction, isolation using RNAeasy midi columns (Qiagen, Valencia, CA) and concentrated by means of Microcon YM-100 centrifugation filters (Millipore, Bedford, MA). The concentration and purity of mRNA was confirmed using 260/280 measurements followed by agarose gel visualization. Samples were subsequently stored at $-80^{\circ} \mathrm{C}$.

cDNA was produced utilizing the TaqMan Gold (Applied Biosystems, Foster City, CA) RT-PCR kit. All RNA samples were reverse transcribed at the same time to reduce variation. Random hexamers transcribed cDNA from $0.2 \mu \mathrm{g}$ of mRNA in a $100 \mu \mathrm{l}$ reaction volume, which were then stored at $-80^{\circ} \mathrm{C}$ until used for real-time PCR analysis. A group of PCR primers was chosen based upon the rat $\beta$ catenin sequence (Suzui et al, 1999). PCR was then used to ascertain the PCR efficiency, and to determine that the correct sequence was being amplified. PAGE-purified intron spanning PCR primers (Lofstrand Labs Limited, Gaithersburg, MD) subsequently chosen for real-time PCR analysis were of the following sequences: $5^{\prime}$-GTC-GAC-AAT-GGCTAC-TCA-AGC-TG- $3^{\prime}$ and $5^{\prime}$-GAG-CTG-TGG-TGG-CACCAG-A-3'. 6-Carboxy-fluorescein (FAM) reporter Taqman probe with 6-carboxy-tetramethyl-rhodamine (TAMRA) quencher was based on Applied Biosystems suggested criteria, and thereafter synthesized by Applied Biosystems. The probe was of the following sequence: $5^{\prime}-6-\mathrm{FAM}-\mathrm{CTC}$ CAT-GGC-CAT-CTC-CAA-CTC-CAT-TAMRA-3'

Samples were repeated in quadruplicates, and the mean values used for subsequent statistical analysis. All real-time PCR reactions were performed using an Applied Biosystems Prism 7700 Sequence Detector. Reactions were performed in Applied Biosystems MicroAmp optical 96-well reaction plates (N801-0560) covered with MicroAmp optical caps (N801-0935) using the Applied Biosystems TaqMan PCR core reagent kit (N808-0228). Optimized PCR conditions were $50^{\circ} \mathrm{C}$ for $2 \mathrm{~min}, 95^{\circ} \mathrm{C}$ for $10 \mathrm{~min}$, followed by 45 cycles of $95^{\circ} \mathrm{C}$ for $15 \mathrm{~s}$ and $63^{\circ} \mathrm{C}$ for $1 \mathrm{~min}$. $\beta$-Catenin probe signal was normalized to a passive ROX reporter, thus developing a normalized reporter signal for a given reaction tube. Standard pools of defined relative concentration were utilized to develop a standard curve (Bustin, 2000), on which experimental values were plotted using proprietary Applied Biosystems software.

Statistical analysis was performed by repeated measure analysis of variance. Reported values are a percent of the control mean. The Student-Newman-Keuls test was used for post hoc analysis. $p<0.05$ was considered significant. Data are expressed as the mean \pm standard error. To ascertain if cDNA from our different treatment groups were amplified equally, Applied Biosystems Taqman Ribomal RNA Control Reagents (which contain primers specific for $18 \mathrm{~S}$ ribosomal RNA and an internal probe that utilizes a VIC reporter/TAMRA quencher) were utilized. 18S reporter signal is also normalized to a passive ROX reporter. Manufacturer's recommendations for assay and PCR conditions were followed. There was no significant change 
in mRNA levels of the $18 \mathrm{~S}$ ribosomal subunit among our samples.

\section{RESULTS}

Cytoplasmic $\beta$-catenin represents the pool that is regulated directly by glycogen synthase kinase; thus, inhibiting GSK-3 increases $\beta$-catenin levels. Rats were treated for 9 days with lithium, valproate, and carbamazepine yielding serum blood levels within the therapeutic range. A period of 9 days was chosen because this approximates the time frame for clinical response in the treatment of mania. ANOVA analysis of densitometry measurements of soluble (representing largely cytoplasmic) $\beta$-catenin levels in the frontal cortex revealed that there was a significant treatment effect $(p=0.0003)$. Post hoc analysis revealed that both lithium and valproate treatment resulted in a significant increase in soluble $\beta$-catenin levels $(p<0.01)$. However, carbamazepine treatment was without effect (Figure 1). In the hippocampus, ANOVA analysis revealed a trend for a difference among groups $(p=0.085)$ (Figure 1$)$.

To determine if the $\beta$-catenin increase was specific for the soluble pool, particulate (representing largely membrane) levels of $\beta$-catenin in the frontal cortex and hippocampus of the same animals used for the analysis of soluble $\beta$-catenin were also analyzed. There was no significant difference among treatments in particulate levels of $\beta$-catenin in either the frontal cortex or the hippocampus (Figure 1). These results suggest that both lithium and valproate selectively regulate the $\beta$-catenin cytoplasmic pool (which acts as a transcription factor) in the rat brain, but do not affect the $\beta$ catenin that interacts with cadherin and is compartmentalized to the cell membrane.

The increase in soluble $\beta$-catenin could be due to either an increase in transcription of $\beta$-catenin or via a posttranscriptional mechanism (eg reduced protein degradation). We hypothesized that if the treatments were increasing $\beta$-catenin levels only through inhibition of GSK-3 (and thereby attenuating $\beta$-catenin protein degradation), $\beta$-catenin mRNA levels would not increase. By contrast, an increase in $\beta$-catenin mRNA levels would suggest that a transcriptional mechanism was also involved. To further delineate the mechanisms underlying the increases in $\beta$-catenin protein levels, a second set of rats were treated with lithium or valproate containing chows for 9 days, and real-time PCR was utilized to quantitate relative mRNA levels in the frontal cortex. ANOVA revealed that there was a significant difference among treatment groups $(p<0.0001)$. Post hoc analysis revealed that lithium treatment resulted in a significant decrease in $\beta$-catenin mRNA $(p<0.001)$, whereas valproate treatment did not produce significant changes in cortex $\beta$-catenin mRNA levels (Figure 2).

\section{DISCUSSION}

In this study, it was observed that in vivo treatment of rats with lithium or valproate for 9 days, at therapeutically relevant concentrations, results in a significant increase in the soluble (representing largely cytoplasm) fraction of $\beta$ catenin protein in the frontal cortex. By contrast, carbama- zepine administration was without effect on $\beta$-catenin protein levels. Furthermore, particulate (representing largely membrane) levels of $\beta$-catenin from the same set of animals were not altered by treatment with any of the medications. To investigate more specifically the mechanisms by which these agents regulate $\beta$-catenin levels, $\beta$ catenin mRNA extracted from frontal cortex tissue of a second set of animals treated with lithium and valproate was analyzed. Consistent with a post-transcriptional mechanism of regulation (ie inhibition of protein degradation), real-time PCR did not demonstrate an increase in $\beta$-catenin mRNA, but rather revealed a small $(\sim 14 \%)$ but significant decrease in $\beta$-catenin mRNA in rats treated with lithium. Since lithium increased total protein levels of $\beta$-catenin in the cytoplasm, the $\beta$-catenin mRNA decrease may represent a compensatory adaptation to the post-transcriptional upregulation of $\beta$-catenin protein levels. These results for the first time identify $\beta$-catenin increase as a common effect of lithium and valproate in vivo. However, it appears that the two medications may act via nonidentical mechanisms to exert these actions.

While we utilized $\beta$-catenin primarily as a marker of GSK3 activity, it is striking that two highly structurally dissimilar mood-stabilizing medications exert similar effects (at therapeutically relevant concentrations) on this important transcription factor (and final stage of the Wnt signaling pathway). However, our finding that carbamazepine did not increase cytosolic $\beta$-catenin levels suggests that an increase in $\beta$-catenin is not a common mechanism by which all mood stabilizers exert their actions. Cell culture and oncogenic studies suggest that increased $\beta$-catenin signaling may be involved in enhancing cell survival (Chen et al, 2001; Hamilton et al, 1995; Huang et al, 2000; Koch et al, 2001). Furthermore, upregulation of a stabilized form of $\beta$-catenin is sufficient to cause the formation of gyri and sulci in the developing mouse brain, a finding observed only in higher mammals, and suggestive of an important role in higher mammalian cognitive functions (Chenn and Walsh, 2002). Another recent study-consistent with these results - reports that overexpression of GSK-3 in the neonatal mouse results in smaller overall brain volume (Spittaels et al, 2002). However, it is not clear if this is due to decreasing $\beta$-catenin levels or to GSK-3's effect on another target. Nevertheless, the data in toto suggest that the upregulation of $\beta$-catenin may play a role in some of the neurotrophic effects of lithium and valproate (Gould and Manji, 2002).

Although both lithium and valproate regulate $\beta$-catenin levels, they may do so by nonidentical mechanisms. Our results strongly suggest that lithium produces a physiologically relevant inhibition of brain GSK-3 at therapeutic serum concentrations. Lithium has also been shown to increase phosphorylation of GSK-3 $\beta$ (Bhat et al, 2000; De Sarno et al, 2002; Lee et al, 2003) and $\alpha$ (Chalecka-Franaszek and Chuang, 1999) at their respective inhibitory serine sites. However, GSK-3 activity toward $\beta$-catenin is not affected by phosphorylation (Ding et al, 2000; Yuan et al, 1999a). Thus, the finding that lithium increases GSK-3 phosphorylation at this phosphorylation site would not be expected to have inhibitory effects on the Wnt pathway, or to increase $\beta$ catenin levels. The mechanism by which the cell achieves separation of GSK-3's activity toward various substrates is 

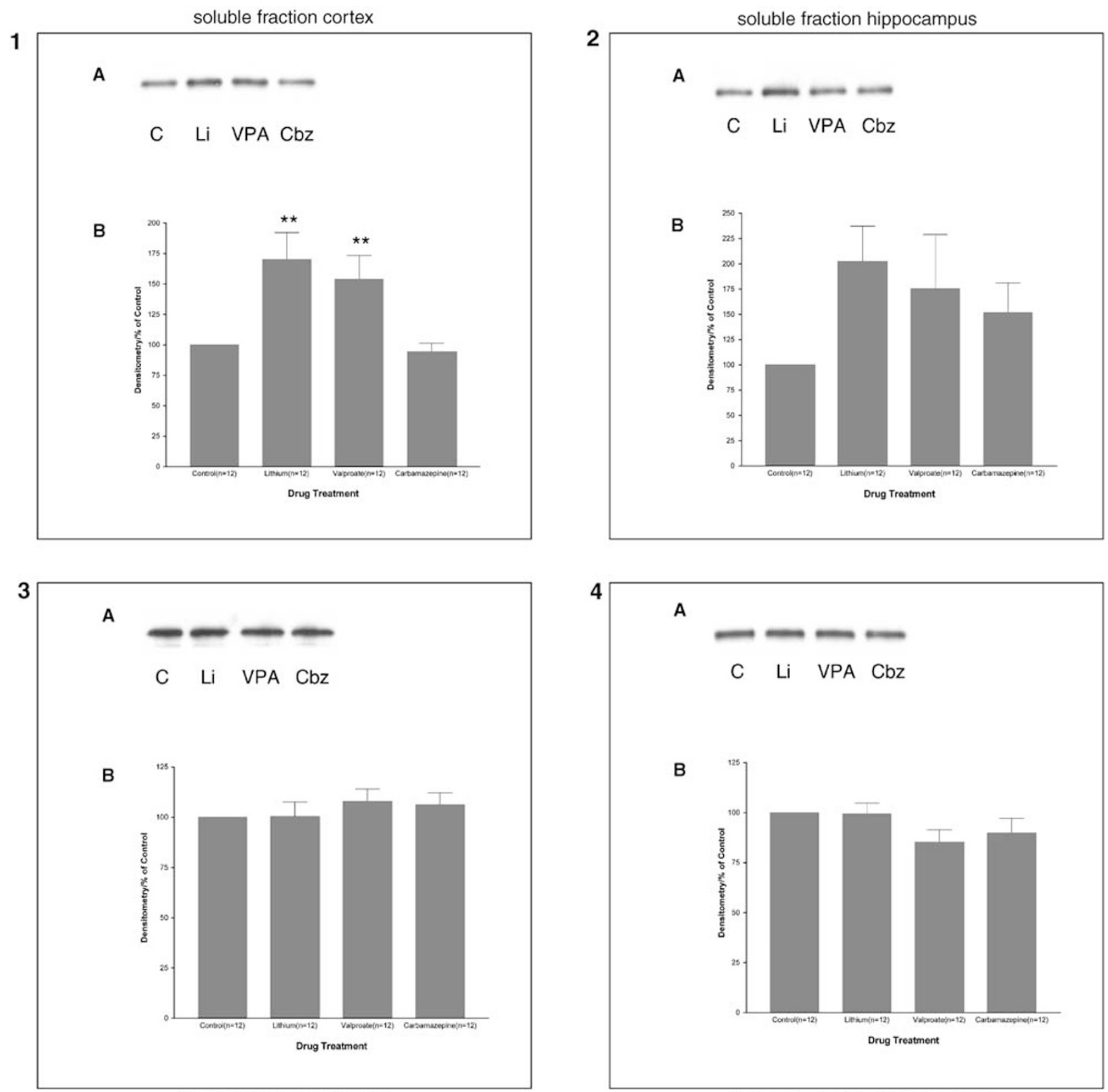

particulate fraction cortex

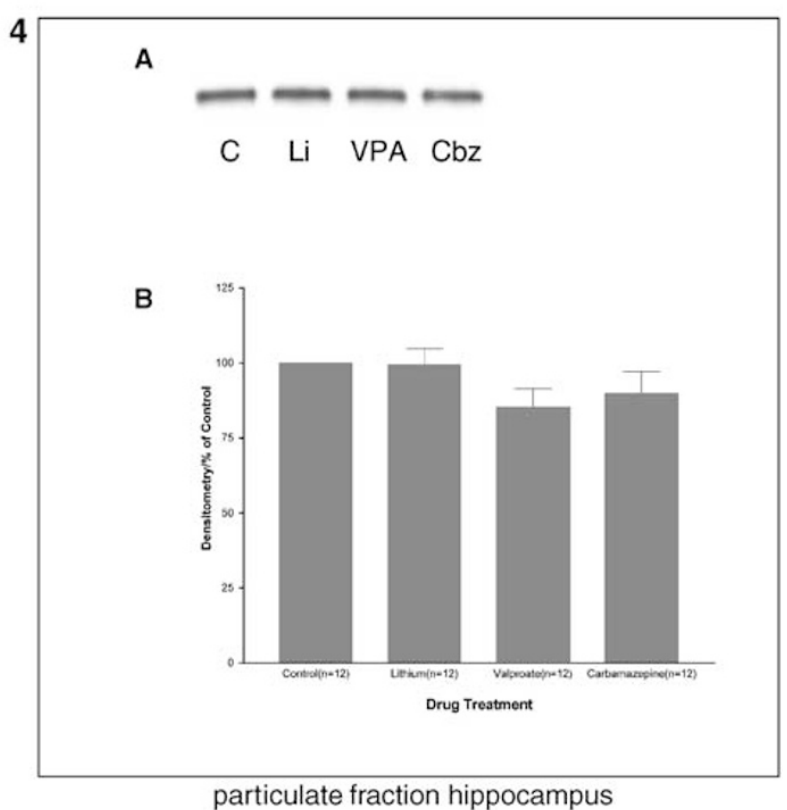

Figure I Lithium and valproate increase soluble $\beta$-catenin levels in rat cortex, without any effect on particulate fractions. Rats were treated for 9 days with control, lithium, valproate, or carbamazepine chows. Soluble (representing largely cytoplasmic) and particulate (representing largely membrane) fractions were extracted from the cortex and hippocampus. The graphs represent densitometry levels of $\beta$-catenin protein in drug treated rats as a percentage of $\beta$ catenin in control chow treated animals. Box I shows a representative Western blot $(I-A)$ and densitometric analysis (I-B) from the cortex soluble fractions. ANOVA revealed that there was a significant difference among the groups $(p=0.0003)$. Student-Newman-Keuls post hoc analysis revealed that both lithium and valproate chows resulted in a significant increase in soluble $\beta$-catenin levels in the frontal cortex of 9-day treated animals when compared to control chow treated rats (lithium, $p<0.0$ I; valproate, $p<0.0$ I). Box 2 shows a representative Western blot $(2-A)$ and densitometric analysis $(2$-B) from the hippocampal soluble fractions. ANOVA revealed that there was a trend toward a difference among the groups $(p=0.085)$. Box 3 shows a representative Western blot (3-A) and densitometric analysis (3-B) from the cortex particulate fractions. ANOVA revealed that there was no significant difference among the groups $(p=0.64 I)$. Box 4 shows a representative Western blot $(4-A)$ and densitometric analysis (4-B) from the hippocampal soluble fractions. ANOVA revealed that there was no significant difference among the groups $(p=0.131)$. $* * * 0.01$.

not known for certain, but it is believed to involve sequestration to different areas of the cell and, at least in the case of the Wnt pathway, interaction within a large protein complex (Cohen and Frame, 2001; Doble and Woodgett, 2003). While lithium appears to regulate the activity of GSK-3 directly, valproate's mechanisms are less clear (see for review Gould and Manji, 2002).

A question that remains to be answered is how the regulation of $\beta$-catenin mRNA directs this protein to its two cellular pools (cytoplasmic and membrane). Our results 


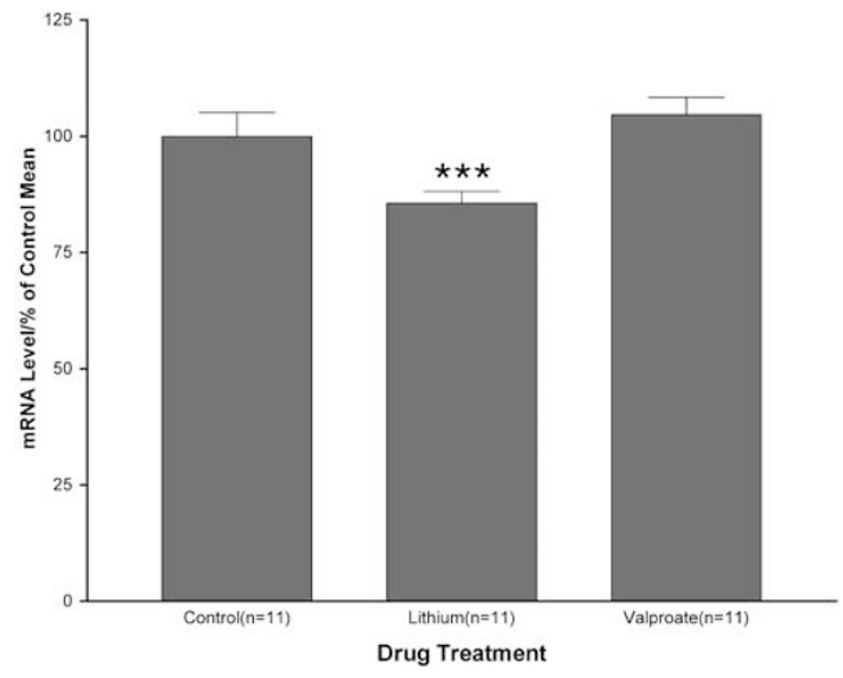

Figure 2 Effects of lithium and valproate on $\beta$-catenin mRNA levels in rat cortex. Rats were treated for 9 days with control, lithium, or valproate chows. Total mRNA was extracted from frontal cortex, and the $\beta$-catenin mRNA levels quantified with real-time PCR. The values represent levels of $\beta$-catenin mRNA in drug treated rats as a percentage of $\beta$-catenin mRNA in control chow treated animals. ANOVA revealed that there was a significant difference among the groups $(p<0.000 \mathrm{I})$. Student-NewmanKeuls post hoc analysis revealed that treatment with lithium chow resulted in a significant decrease in $\beta$-catenin mRNA levels in the frontal cortex of 9day treated animals compared to rats treated with either control or valproate chow $(p<0.00 I)$. Valproate treatment resulted in no significant change in $\beta$-catenin mRNA levels compared to control chow treated rats. ***** $p<0.001$

suggest that a mechanism of differential regulation does occur. Indeed, in this study, lithium was able to decrease $\beta$ catenin mRNA levels without decreasing particulate (membrane) protein levels. It is currently unknown if the two pools are regulated by different splice variants, different promoters, or other targeting mechanisms, which direct subcellular compartmentalization of $\beta$-catenin.

Many pharmaceutical companies are actively developing small-molecule inhibitors of GSK-3. A number of drug compounds, including the general classes of hymenialdisines, paullones, indirubines, maleimides, and thiaziazolidiones, have been developed as potent and specific GSK-3 inhibitors (Dorronsoro et al, 2002; Martinez et al, 2002). Much of the emphasis for the development of GSK-3 inhibitors appears to be for the treatment of diabetes, Alzheimer's disease, stroke, and inflammation; GSK-3's role as a kinase that deactivates glycogen synthase may be useful in lowering blood sugar and treating diabetes, phosphorylation of tau by GSK-3 may advance the formation of neurofibrillary tanges, and GSK-3's general effects on apoptosis and regulation of nuclear factor $-\kappa \mathrm{B}(\mathrm{NF}-\kappa \mathrm{B})$ may have utility for the treatment of stroke and inflammation (Cohen and Frame, 2001; Eldar-Finkelman, 2002; Frame and Cohen, 2001; Woodgett, 2001). Based on accumulating evidence, including the data presented here, GSK-3 inhibitors are likely candidates for novel bipolar disorder treatments. Thus, we would suggest that smallmolecule, brain penetrant, GSK-3 inhibitors that are developed for these other disorders should also undergo clinical trials for the treatment of bipolar disorder.

\section{ACKNOWLEDGEMENTS}

We would like to acknowledge the support of the Intramural Research Program of the National Institute of Mental Heath, the Stanley Medical Research Institute, and the National Alliance for Research on Schizophrenia and Depression.

\section{REFERENCES}

Amari L, Layden B, Nikolakopoulos J, Rong Q, Mota de Freitas D, Baltazar $\mathrm{G}$ et al (1999a). Competition between $\mathrm{Li}^{+}$and $\mathrm{Mg}^{2+}$ in neuroblastoma SH-SY5Y cells: a fluorescence and 31P NMR study. Biophys J 76: 2934-2942.

Amari L, Layden B, Rong Q, Geraldes CF, Mota de Freitas D (1999b). Comparison of fluorescence, (31)P NMR, and (7)Li NMR spectroscopic methods for investigating $\mathrm{Li}(+) / \mathrm{Mg}(2+)$ competition for biomolecules. Anal Biochem 272: $1-7$.

Bhat RV, Shanley J, Correll MP, Fieles WE, Keith RA, Scott CW et al (2000). Regulation and localization of tyrosine216 phosphorylation of glycogen synthase kinase-3beta in cellular and animal models of neuronal degeneration. Proc Natl Acad Sci USA 97: 11074-11079.

Bradford MM (1976). A rapid and sensitive method for the quantitation of microgram quantities of protein utilizing the principle of protein-dye binding. Anal Biochem 72: 248-254.

Brocard JB, Rajdev S, Reynolds IJ (1993). Glutamate-induced increases in intracellular free $\mathrm{Mg}^{2+}$ in cultured cortical neurons. Neuron 11: 751-757.

Bustin SA (2000). Absolute quantification of mRNA using realtime reverse transcription polymerase chain reaction assays. $J$ Mol Endocrinol 25: 169-193.

Chalecka-Franaszek E, Chuang DM (1999). Lithium activates the serine/threonine kinase Akt-1 and suppresses glutamate-induced inhibition of Akt-1 activity in neurons. Proc Natl Acad Sci USA 96: 8745-8750.

Chen S, Guttridge DC, You Z, Zhang Z, Fribley A, Mayo MW et al (2001). Wnt-1 signaling inhibits apoptosis by activating betacatenin/T cell factor-mediated transcription. J Cell Biol 152: 87-96.

Chenn A, Walsh CA (2002). Regulation of cerebral cortical size by control of cell cycle exit in neural precursors. Science 297: 365-369.

Cohen P, Frame S (2001). The renaissance of GSK3. Nat Rev Mol Cell Biol 2: 769-776.

Davies SP, Reddy H, Caivano M, Cohen P (2000). Specificity and mechanism of action of some commonly used protein kinase inhibitors. Biochem J 351: 95-105.

De Sarno P, Li X, Jope RS (2002). Regulation of Akt and glycogen synthase kinase-3beta phosphorylation by sodium valproate and lithium. Neuropharmacology 43: 1158-1164.

Ding VW, Chen RH, McCormick F (2000). Differential regulation of glycogen synthase kinase 3beta by insulin and Wnt signaling. J Biol Chem 275: 32475-32481.

Doble BW, Woodgett JR (2003). GSK-3: tricks of the trade for a multi-tasking kinase. J Cell Sci 116: 1175-1186.

Dorronsoro I, Castro A, Martinez A (2002). Inhibitors of glycogen synthase kinase-3: future therapy for unmet medical needs. Expert Opin Ther Patents 12: 1527-1536.

Eldar-Finkelman H (2002). Glycogen synthase kinase 3: an emerging therapeutic target. Trends Mol Med 8: 126-132.

Elyaman W, Terro F, Wong NS, Hugon J (2002). In vivo activation and nuclear translocation of phosphorylated glycogen synthase kinase-3beta in neuronal apoptosis: links to tau phosphorylation. Eur J Neurosci 15: 651-660.

Frame S, Cohen P (2001). GSK3 takes centre stage more than 20 years after its discovery. Biochem J 359: 1-16. 
Gee II JB, Corbett RJ, Perlman JM, Laptook AR (2001). Hypermagnesemia does not increase brain intracellular magnesium in newborn swine. Pediatr Neurol 25: 304-308.

Gotoh H, Kajikawa M, Kato H, Suto K (1999). Intracellular $\mathrm{Mg}^{2+}$ surge follows $\mathrm{Ca}^{2+}$ increase during depolarization in cultured neurons. Brain Res 828: 163-168.

Gould TD, Chen G, Manji HK (2002). Mood stabilizer psychopharmacology. Clin Neurosci Res 2: 193-212.

Gould TD, Manji HK (2002). The wnt signaling pathway in bipolar disorder. Neuroscientist 8: 497-511.

Grimes CA, Jope RS (2001). The multifaceted roles of glycogen synthase kinase 3beta in cellular signaling. Prog Neurobiol 65: 391-426.

Gurvich N, Klein PS (2002). Lithium and valproic acid: parallels and contrasts in diverse signaling contexts. Pharmacol Ther 96: 45-66.

Hamilton SR, Liu B, Parsons RE, Papadopoulos N, Jen J, Powell SM et al (1995). The molecular basis of Turcot's syndrome. $N$ Engl J Med 332: 839-847.

Huang H, Mahler-Araujo BM, Sankila A, Chimelli L, Yonekawa Y, Kleihues $\mathrm{P}$ et al (2000). APC mutations in sporadic medulloblastomas. Am J Pathol 156: 433-437.

Klein PS, Melton DA (1996). A molecular mechanism for the effect of lithium on development. Proc Natl Acad Sci USA 93: 8455-8459.

Koch A, Waha A, Tonn JC, Sorensen N, Berthold F, Wolter M et al (2001). Somatic mutations of WNT/wingless signaling pathway components in primitive neuroectodermal tumors. Int J Cancer 93: 445-449.

Lee CW, Lau KF, Miller CC, Shaw PC (2003). Glycogen synthase kinase-3beta-mediated tau phosphorylation in cultured cell lines. Neuroreport 14: 257-260.

Lee Y, Hamamura T, Ohashi K, Miki M, Fujiwara Y, Kuroda S (2000). Carbamazepine suppresses methamphetamine-induced Fos expression in a regionally specific manner in the rat brain. Possible neural substrates responsible for antimanic effects of mood stabilizers. Neuropsychopharmacology 22: 530-537.

Li-Smerin Y, Levitan ES, Johnson JW (2001). Free intracellular $\mathrm{Mg}(2+)$ concentration and inhibition of NMDA responses in cultured rat neurons. J Physiol 533: 729-743.

Marangos PJ, Weiss SR, Montgomery P, Patel J, Narang PK, Cappabianca AM et al (1985). Chronic carbamazepine treatment increases brain adenosine receptors. Epilepsia 26: 493-498.

Martinez A, Castro A, Dorronsoro I, Alonso M (2002). Glycogen synthase kinase 3 (GSK-3) inhibitors as new promising drugs for diabetes, neurodegeneration, cancer, and inflammation. Med Res Rev 22: 373-384.

Masuda CA, Xavier MA, Mattos KA, Galina A, Montero-Lomeli M (2001). Phosphoglucomutase is an in vivo lithium target in yeast. J Biol Chem 10: 10.

Munoz-Montano JR, Moreno FJ, Avila J, Diaz-Nido J (1997). Lithium inhibits Alzheimer's disease-like tau protein phosphorylation in neurons. FEBS Lett 411: 183-188.

Peifer M, Polakis P (2000). Wnt signaling in oncogenesis and embryogenesis - a look outside the nucleus. Science 287: 1606-1609.

Phiel CJ, Klein PS (2001). Molecular targets of lithium action. Annu Rev Pharmacol Toxicol 41: 789-813.
Planel E, Yasutake K, Fujita SC, Ishiguro K (2001). Inhibition of protein phosphatase $2 \mathrm{~A}$ overrides Tau protein kinase I/glycogen synthase kinase $3 \mathrm{~b}$ and cyclin-dependant kinase 5 inhibition and results in tau hyperphosphorylation in the hippocampus of starved mouse. J Biol Chem 5: 5.

Ray Jr WJ, Szymanki ES, Ng L (1978). The binding of lithium and of anionic metabolites to phosphoglucomutase. Biochim Biophys Acta 522: 434-442.

Rhyu GI, Ray Jr WJ, Markley JL (1984). Enzyme-bound intermediates in the conversion of glucose 1-phosphate to glucose 6-phosphate by phosphoglucomutase. Phosphorus NMR studies. Biochemistry 23: 252-260.

Ryves WJ, Harwood AJ (2001). Lithium inhibits glycogen synthase kinase- 3 by competition for magnesium. Biochem Biophys Res Commun 280: 720-725.

Shaldubina A, Agam G, Belmaker RH (2001). The mechanism of lithium action: state of the art, ten years later. Prog Neuropsychopharmacol Biol Psychiatry 25: 855-866.

Sharpe C, Lawrence N, Martinez Arias A (2001). Wnt signalling: a theme with nuclear variations. BioEssays 23: 311-318.

Spittaels K, Van den Haute C, Van Dorpe J, Terwel D, Vandezande $\mathrm{K}$, Lasrado R et al (2002). Neonatal neuronal overexpression of glycogen synthase kinase-3beta reduces brain size in transgenic mice. Neuroscience 113: 797.

Stambolic V, Ruel L, Woodgett JR (1996). Lithium inhibits glycogen synthase kinase-3 activity and mimics wingless signalling in intact cells. Curr Biol 6: 1664-1668.

Suzui M, Ushijima T, Dashwood RH, Yoshimi N, Sugimura T, Mori $\mathrm{H}$ et al (1999). Frequent mutations of the rat betacatenin gene in colon cancers induced by methylazoxymethanol acetate plus 1-hydroxyanthraquinone. Mol Carcinogen 24: 232-237.

Weiss SR, Nguyen T, Rubinow DR, Helke CJ, Narang PK, Post RM et al (1987). Lack of effect of chronic carbamazepine on brain somatostatin in the rat. J Neural Transm 68: 325-333.

Weiss SR, Post RM (1987). Carbamazepine and carbamazepine10,11-epoxide inhibit amygdala-kindled seizures in the rat but do not block their development. Clin Neuropharmacol 10: 272-279.

Wodarz A, Nusse R (1998). Mechanisms of Wnt signaling in development. Annu Rev Cell Dev Biol 14: 59-88.

Woodgett JR (2001). Judging a protein by more than its name: gsk-3. Sci STKE 2001: RE12.

York JD, Ponder JW, Majerus PW (1995). Definition of a metaldependent/Li(+)-inhibited phosphomonoesterase protein family based upon a conserved three-dimensional core structure. Proc Natl Acad Sci USA 92: 5149-5153.

Yuan H, Mao J, Li L, Wu D (1999a). Suppression of glycogen synthase kinase activity is not sufficient for leukemia enhancer factor-1 activation. J Biol Chem 274: 30419-30423.

Yuan P, Chen G, Manji HK (1999b). Lithium activates the c-Jun $\mathrm{NH} 2$-terminal kinases in vitro and in the CNS in vivo. $J$ Neurochem 73: 2299-2309.

Yuan PX, Huang LD, Jiang YM, Gutkind JS, Manji HK, Chen G (2001). The mood stabilizer valproic acid activates mitogenactivated protein kinases and promotes neurite growth. J Biol Chem 276: 31674-31683. 